Mountaineering as affect regulation: the moderating role of self-regulation strategies.

Castanier, C.; Le Scanff, C.; Woodman, Tim

\title{
Anxiety, Stress and Coping
}

DOI:

$10.1080 / 10615801003774210$

Published: 13/04/2010

Peer reviewed version

Cyswllt i'r cyhoeddiad / Link to publication

Dyfyniad o'r fersiwn a gyhoeddwyd / Citation for published version (APA):

Castanier, C., Le Scanff, C., \& Woodman, T. (2010). Mountaineering as affect regulation: the moderating role of self-regulation strategies. Anxiety, Stress and Coping, 24(1), 75-89.

https://doi.org/10.1080/10615801003774210

\section{Hawliau Cyffredinol / General rights}

Copyright and moral rights for the publications made accessible in the public portal are retained by the authors and/or other copyright owners and it is a condition of accessing publications that users recognise and abide by the legal requirements associated with these rights. study or research.

- Users may download and print one copy of any publication from the public portal for the purpose of private

- You may not further distribute the material or use it for any profit-making activity or commercial gain

- You may freely distribute the URL identifying the publication in the public portal ?

Take down policy

This is an Accepted Manuscript of an article published by Taylor \& Francis in Anxiety, Stress and Coping on 13th April 2010, available online: http://www.tandfonline.com/doi/abs/10.1080/10615801003774210

Take down policy

If you believe that this document breaches copyright please contact us providing details, and we will remove access to the work immediately and investigate your claim. 
1 Running Head: AFFECT REGULATION IN MOUNTAINEERING

3 Article accepted in its current form in Anxiety, Stress, and Coping:

4 Castanier, C., Le Scanff, C., \& Woodman, T. (2011). Mountaineering as affect regulation: the 5 moderating role of self-regulation strategies. Anxiety, Stress, and Coping, 24, 75-89.

Mountaineering as affect regulation: the moderating role of self-regulation strategies

21 *Correspondence concerning this article should be addressed to: Carole Castanier,

22 Université Paris-Sud 11, UFR STAPS, Bât 335, F-91405 Orsay Cedex. Telephone: + 33 (0)1 69

231531 08. Fax: + 33 (0)1 691562 22. E-mail: carole.castanier@u-psud.fr. 
Abstract

2 We investigated the change in mountaineers' affect from pre- to post-mountain route and the

3 moderating role of self-regulation strategies in this process. First, we hypothesized that

4 engagement in a high-risk sport such as mountaineering would lead to a decrease in negative

5 affect and an increase in positive affect and that this affect regulation would be moderated by

6 self-regulation strategies (escape from self-awareness and compensation). Second, we predicted

7 that the self-regulation affect process would be specifically associated with high-risk sport rather

8 than sport generally. One hundred and five mountaineers and 73 judokas completed the Risk and

9 Excitement Inventory and the Positive and Negative Emotions Scale before and after completing

10 their activity (mountain route or judo fight). Regression analyses revealed that anxiety

11 significantly decreased from pre- to post-mountain route and that the self-regulation of escape

12 from awareness yielded a significantly greater anxiety decrease. No such interaction emerged for

13 the compensation strategy and no effects were revealed for judokas. Results are discussed in

14 terms of the specificity of the high-risk sport domain in its ability to serve an affect regulation

15 function for those individuals who seek to escape from self-awareness.

16

17 Key words: Affect change, anxiety, risk-taking, escape, compensation, high-risk sports 
Mountaineering as affect regulation: the moderating role of self-regulation strategies

Much research has been devoted to understanding the adoption of the disinhibition

3 behaviors associated with socially unacceptable volitional behaviors with a significant risk to

4 one's health (e.g., dangerous driving, drug taking, promiscuous sex). Relatively sparse research,

5 however, has been devoted to socially accepted behaviors in which the danger is recognized and

6 controlled (e.g., high-risk jobs, high-risk sports; Turner, McClure, \& Pirozzo, 2004). The focus of

7 the current study is on this socially accepted end of the spectrum and more specifically on high-

8 risk sports that are defined as sports where one accepts the possibility of severe injury or death as

9 an inherent part of the activity (Breivik, 1995; Llewellyn \& Sanchez, 2008).

10 Most studies of individual differences and the propensity to risk-taking have been

11 conducted within a sensation seeking framework. In fact, the study of risk taking has become

12 nearly synonymous with sensation seeking theory (Ferrando \& Chico, 2001; Jackson \& Maraun,

13 1996). Sensation seeking is viewed as a motivation for involvement in risk-taking behaviors

14 inasmuch as these are an obvious way to experience various sensations that increase

15 physiological arousal (Arnett, 1996; Zuckerman, 1994). A large body of research evidence

16 confirms that sensation seeking is positively linked with the participation in a wide range of risk-

17 taking behaviors including disinhibition activities (e.g., Hoyle, Fejfar, \& Miller, 2000; Jelalian,

18 Alday, Spirito, Rasile, \& Nobile, 2000; Van Hasselt, Null-Tracy Kempton, \& Bukstein, 1993)

19 and high-risk sports (e.g., Llewellyn \& Sanchez, 2008; Michel, Carton, \& Jouvent, 1997;

20 Zuckerman, 2007). Despite the popularity of sensation seeking theory, a number of concerns

21 have been raised relating to its conceptual and empirical basis (Jackson \& Maraun, 1996; Slanger

22 \& Rudestam, 1997). For example, although sensation seeking may partially explain risk-taking,

23 the proportion of explained variance appears to be relatively small (Himelstein \& Thorne, 1985;

24 Horvath \& Zuckerman, 1993). Furthermore, sensation seeking theory does not adequately 
1 account for the full range of motives mentioned by risk takers themselves for participating in

2 high-risk activities (Cazenave, Le Scanff, \& Woodman, 2007; Ewert, 1994; Shapiro, Siegel,

3 Scovill, \& Hays, 1998; Woodman, Hardy, \& O'Brien, 2005).

4 In addition to the management of arousal states, risk-taking behaviors can serve many

5 different goals or functions (Cooper, Agocha, \& Sheldon, 2000). For example, people may

6 engage in these behaviors to regulate their affects (Cooper, Shapiro, \& Powers, 1998). Although

7 there are many proposed definitions of affect regulation, most include the notion that, in the

8 process of monitoring and evaluating affective states, individuals take actions either to maintain

9 or to change (enhance or suppress) the intensity of affect, or to prolong or shorten the affective

10 episode (Gross, 1999; Parkinson, Totterdell, Briner, \& Reynolds, 1996; Thompson, 1994).

11 Affective states influence cognition, behavior, and experience (Bless \& Forgas, 2000) and one

12 function of affect regulation is thought to be to limit the residual impact of lingering emotions on

13 subsequent behavior and experience (Larsen \& Prizmic, 2004). Larsen (2000) posits that people

14 regulate affect to achieve a super-ordinate goal: to maintain a global sense of subjective well-

15 being. According to some authors (e.g., Diener \& Seligman, 2002), subjective well-being has two

16 affective components at its core, both of which are considered as aggregates over relatively long

17 time periods. These two components are positive affect and negative affect. Affect regulation can

18 thus be conceptualized as a $2 \times 2$ affect (positive and negative affect) and change (increase and

19 decrease) model, in which the most obvious regulation strategies are to increase positive affect

20 and to decrease negative affect (Larsen \& Prizmic, 2004). Risk-taking behaviors may result from

21 a desire to avoid or reduce negative affect and to pursue or enhance positive affect (Cooper et al.,

22 2000). In this way, these behaviors may reflect a means of affect regulation that is not perceived

23 to be readily available elsewhere (Barlow, Hardy, \& Woodman, 2007; Taylor \& Hamilton, 1997;

24 Woodman et al., 2005; Woodman, Huggins, Le Scanff, \& Cazenave, 2009). In fact, some authors 
1 posit that high-risk sport may be more attractive than other sports for anxious individuals, as it

2 affords them an opportunity to experience and subsequently control their intense anxiety

3 (Fenichel, 1939; Woodman, Cazenave, \& Le Scanff, 2008).

4 Several researchers have proposed models for the process of affect regulation. For

5 example, self-regulation theory (Carver \& Scheier, 1981) and its derivatives (Hamilton,

6 Greenberg, Pyszczynski, \& Cather, 1993; Pyszczynski, Greenberg, Solomon, \& Hamilton, 1991)

7 are based on the theory of objective self-awareness (Duval \& Wicklund, 1972). One of the most

8 important consequences of self-awareness is the activation of goal-directed behavior. The theory

9 states that the awareness of discrepancies between one's goal in a particular situation or task and

10 one's current status in relation to that goal leads to negative affect. Purposeful action is viewed as

11 an attempt to reduce such discrepancies and any associated negative affect. Duval and Wicklund

12 (1972) argued that the easiest way to reduce negative affect is to disengage from the failed task or

13 activity and then to turn attention away from the self. In support of this position, these authors

14 have shown that individuals who are exposed to contrived failure experiences engage in actions

15 that reduce their level of self-awareness. However, according to Pyszczynski et al. (1991) there

16 are two possible strategies for self-regulation. One can indeed escape from self-awareness, but

17 one can also make a compensatory shift to another activity in which success is more likely, but

18 which serves the same abstract goal as the failed activity (e.g., self-worth).

19 Based on Carver and Scheier's (1981) theory of self-regulation and its extensions

20 (Hamilton et al., 1993; Pyszczynski et al., 1991), Taylor and Hamilton (1997) suggested that risk-

21 taking behaviors may serve either of these two self-regulatory strategies, each with the same goal

22 of maintaining a global sense of well-being (Larsen, 2000); some risk-taking behaviors may serve

23 an escape function, whereas others may serve a compensation function. For example,

24 involvement in socially unaccepted risk-taking behaviors such as alcohol abuse and drug taking 
1 appear to serve largely an escape function because such activities allow individuals to shift

2 attention away from their self-ideal discrepancy (Taylor \& Hamilton, 1997). Conversely, more

3 socially accepted risk-taking behaviors such as high-risk sports, which are activities that typically

4 require careful training and preparation and in which risk is controlled, may serve more a

5 compensation function (Taylor \& Hamilton, 1997). These risk-taking activities provide a way for

6 individuals to maintain a particular self-image, or to enhance self-esteem, which are benefits that

7 they do not necessarily derive in other life domains (e.g., work, family; Barlow et al., 2007;

8 Taylor \& Hamilton, 1997). Recent research, however, suggests that the picture is not quite this

9 straightforward and that high-risk sports may also serve an escape from self-awareness function

10 (Cazenave et al., 2007; Lafollie \& Le Scanff, 2007). There is thus a need to investigate these

11 escape and compensation strategies within the high-risk sport domain rather than assuming that

12 all high-risk sport participants engage in their sport for the same affect regulation purposes.

13 Although authors have suggested that high-risk sports might serve an affect regulation

14 function (e.g., Cazenave et al., 2007; Michel et al., 1997; Taylor \& Hamilton, 1997; Woodman,

15 Hardy, Barlow, \& Le Scanff, 2010), few studies have directly investigated this process. In fact,

16 only two studies have reported a specific decrease in anxiety as a direct consequence of

17 engagement in high-risk sport (skydiving), particularly for people with emotion difficulties

18 (Woodman et al., 2008; Woodman et al., 2009). To the best of our knowledge, no study has

19 investigated the effect of high-risk sport participation on other negative affects and more widely

20 on the global model of emotional well-being (i.e., positive and negative affects; Diener \&

21 Seligman, 2002). Specifically, as noted by Woodman et al. (2008), it remains to be elucidated

22 whether the high-risk sport domain serves only to reduce negative affect, or whether it also

23 increases positive affect. Furthermore, the role of self-regulation strategies (Taylor \& Hamilton, 
1 1997) in this process has received no research attention. The aim of the current study is to bridge

2 these gaps.

3 In the first hypothesis we predicted that engagement in a high-risk sport (e.g., mountain

4 climbing) would lead specifically to a decrease in anxiety (cf. Woodman et al., 2008; Woodman

5 et al., 2009), but also in other negative affect; and an increase in positive affect (Carver \&

6 Scheier, 1981; Cooper et al., 2000). Second, we hypothesized that this affect change would be

7 moderated by self-regulation strategies. Specifically, according to Taylor and Hamilton (1997),

8 high escape individuals have emotional distress (e.g., a general tendency to feel negative affects)

9 that they attempt to cope with by engaging in a high-risk activity. Thus, we predicted that

10 mountaineers high in escape motive would experience a decrease in their negative affective state,

11 specifically in anxiety (Cazenave et al., 2007; Lafollie \& Le Scanff, 2007; Woodman et al.,

12 2009). Conversely, Taylor and Hamilton (1997) reported that compensation was not associated

13 with emotional difficulties. Thus, we hypothesized that mountaineers high in compensation

14 motive would enjoy an increase in positive affect linked to a sense of achievement in their sports

15 activities. Finally, given that the high-risk sport domain may attract some individuals with

16 emotion regulation difficulties specifically on the basis of its ability to induce intense anxiety

17 (Fenichel, 1939; Woodman et al., 2008), we hypothesized that the anxiety self-regulation process

18 would hold specifically for high-risk sport rather than for all sports.

Method

\section{Participants}

21 Two hundred and twenty sportsmen were approached in person and asked to take part in

22 the study. Of the 189 persons who agreed to participate in the study, eight did not provide data at

23 Time 2. After having further excluded three outlier participants, we obtained complete sets of 
1 data from 178 sportsmen divided in two groups: one group of male mountaineers $\left(n=105 ; M_{\text {age }}=\right.$

229.07 years; $S D=5.46)$ and one group of male judokas $\left(n=73 ; M_{\text {age }}=18.79\right.$ years; $\left.S D=2.16\right)$.

3 Measures

Self-regulation strategies. Self-regulation strategies were measured with the Risk and

5 Excitement Inventory (Taylor \& Hamilton, 1997) validated in French by Lafollie, Le Scanff, and

6 Fontayne (2008). This inventory comprises two subscales that assess two distinct self-regulation

7 strategies: compensation (e.g., "I am more aware of myself as a person when engaged in exciting

8 activities") and escape (e.g., "When I take risks I lose myself more than usual"). The final

9 version of the French inventory contains 12 items (six for escape, and six for compensation),

10 which are scored on a five-point Likert scale, ranging from 1 (not at all true) to 5 (totally true).

11 This instrument showed acceptable internal reliability in the French validation study (Lafollie et

12 al., 2008; Cronbach alpha of .77 for compensation and .69 for escape) as well as in the present

13 study (.80 for compensation and .71 for escape).

14 Negative affectivity. Negative affectivity was assessed via the trait version of the two-

15 factor Positive and Negative Emotionality Inventory (Pelissolo, Rolland, Perez-Diaz, Jouvent, \&

16 Allilaire, 2007), an affect self-report scale adapted from Diener, Smith, and Fujita (1995)

17 questionnaire. We used only negative affectivity for the purpose of this study. The negative

18 affectivity factor of this instrument comprises 18 items rated on a seven-point Likert scale from 1

19 (never) to 7 (several times per day), assessing individuals' general tendency to feel negative

20 affects. This sub-scale showed good internal reliability in the validation study (Pelissolo et al.,

21 2007; Cronbach alpha of .93) as well as in the present study (Cronbach alpha of .91).

Affective states. Affective states were measured with the state form of the Positive and

23 Negative Emotions Scale (Pelissolo et al., 2007). This instrument contains 28 items assessing six 24 specific affect states (joy, affection, anxiety, anger, shame, sadness). The measure contains 
1 adjectives that describe these affective states, and participants indicate to what extent they feel

2 each item at this moment using a seven-point Likert scale ranging 1 (not at all) to 7 (very much).

3 This instrument showed adequate internal reliability in the validation study (Pelissolo et al., 2007;

4 Cronbach alpha ranged from .81 to .93) as well as in the present study (Cronbach alpha .70 -.89).

\section{Procedure}

6 The initial contact with participants in the National French School of Skiing and

7 Mountaineering and in two Judo French Poles included a brief presentation of the study purpose

8 with an explanation of the procedure, and an assurance of confidentiality. Participants were told

9 simply that the study was an investigation of affective states. The data were collected at two

10 different times. First, after completing consent forms, a short demographic questionnaire, the

11 Risk and Excitement Inventory and the Positive and Negative Emotions Scale Trait Form,

12 participants were asked to complete the Positive and Negative Emotions Scale State Form a first

13 time (T1) approximately 30 minutes before they started their activity (mountain route or judo

14 fight). Second, we asked participants to complete the Positive and Negative Emotions Scale State

15 Form a second time (T2) as soon as was feasible after the end of their activity (approximately one 16 hour).

Results

The assumptions of parametric and multivariate analysis (cf. Tabachnick \& Fidell, 2001)

19 were satisfied for the present data set. Age was associated with some of the study variables (e.g.,

20 escape self-regulation strategy, $r=-.28, p<.01$ ) and the two groups differed significantly on age

$21(t(176)=18.34, p<.001)$. Consequently, we controlled for age in each subsequent analysis.

23 Taylor and Hamilton (1997), escape was significantly correlated with negative affectivity (i.e., 
1 significantly related with this emotional variable $(r=.13, n s)$. Furthermore, the escape mean for

2 mountaineers $(M=13.45, S D=3.67)$ was not significantly different to that of judokas $(M=$

$315.18, S D=3.94)$ after controlling for age; $F(1,175)=0.08, p>.05$, but was significantly lower

4 than that of the French norm $(M=17.00 ; S D=4.87$; Lafollie et al., 2008), $t(104)=9.91, p<$

5.001 . The compensation mean for mountaineers $(M=23.19, S D=4.16)$ was significantly higher

6 than that of the judokas $(M=21.42, S D=4.90)$ after controlling for age, $F(1,175)=4.97, p<$

7.05 , but was not significantly different to that of the French norms $(M=22.86, S D=4.17$;

$8 \quad$ Lafollie et al., 2008); $t(104)=0.80)$.

9 The analyses were performed separately for each affective state (i.e., anxiety, anger,

10 shame, sadness, joy and affection) and each self-regulation strategy (i.e., escape and

11 compensation).

12 Mountaineers' change in affect

13 To investigate the overall effect of mountaineering on mountaineers' affective states,

14 single-factor repeated measures (pre/post mountain route) ANCOVAs were conducted with each

15 affect as the dependent variable and age as the covariate (see Table 2).

16 Negative affects. ANCOVAs revealed a significant difference for anxiety and not for the

17 other negative affects (anger, shame, and sadness). Participants felt significantly less anxiety

18 post-mountain route $(M=11.22, S D=9.89)$ compared to pre-mountain route $(M=17.48, S D=$

$1910.57), F(1,103)=4.39, p<.05, \eta^{2}=.04$.

20 Positive affects. ANCOVAs revealed no significant difference between pre- and post-

21 mountain route for positive affect states (joy and affection).

22 The moderating role of self-regulation strategies in mountaineers' affective change 
To examine the potential moderation of self-regulation strategies (escape and

2 compensation) on mountaineers' affective change, we performed regression analyses following

3 procedures explained by Judd, Kenny and McClelland (2001). All variables were centered before

4 being subjected to regression analyses. For each regression analysis, age was controlled at Step 1

5 and self-regulation strategy (i.e., escape or compensation) was entered at Step 2.

6 Escape. Of all the affects (anxiety, anger, shame, sadness, joy, and affection), only the

7 regression analysis for anxiety revealed a significant Escape $\times$ Time interaction (see Table 3 ).

8 After controlling for age, regressing each anxiety score on escape yielded $\hat{Y}_{1 i}=1.74+1.02$

9 Escape $_{i}$ and $\hat{Y}_{2 i}=6.26+0.15$ Escape $_{i}$. In the first equation, Escape was a significant predictor of

$10 Y_{1}$ (i.e., pre-mountain route anxiety), $t(102)=3.68, p<.001, \eta^{2}=.12$; in the second equation

11 (i.e., post-mountain route anxiety), the slope for Escape was not significantly different from zero,

$12 t(102)=0.56, p>.50, \eta^{2}=.00$. Regressing the anxiety difference, $Y_{d}\left(Y_{2}-Y_{1}\right)$, on Escape yielded

13 the following equation: $\hat{Y}_{d i}=4.53-0.87$ Escape $_{i}$. Here the slope for Escape was significantly

14 different from zero, $t(102)=3.06, p<.01, \eta^{2}=.08$. The test of whether this slope differs from

15 zero is equivalent to showing that the slope for Escape in the $Y_{2}$ equation differs from the slope

16 for Escape in the $Y_{1}$ equation. This significant Escape $\times$ Time interaction shows that higher

17 escape profiles yielded greater decreases in anxiety from pre- to post-mountain route, as

18 hypothesized.

19 Compensation. The regression analysis revealed no significant Compensation $\times$ Time

20 interactions for any affects (see Table 3).

21 Specificity of high-risk sport in anxiety self-regulation

22 To investigate the specificity of high-risk sport (i.e., mountaineering vs. judo) in anxiety

23 change, a 2 (Activity: mountaineers/judokas) x 2 (Time: pre/post activity) ANCOVA with 
1 repeated measures on the second factor was conducted with anxiety as the dependent variable and

2 age as covariate. The analysis revealed a significant main effect for Time, $F(1,175)=6.97, p<$

$3.01, \eta^{2}=.04$, such as participants felt significantly more anxiety before than after activity.

4 Conversely, no significant main effect appeared for Activity, $F(1,175)=0.02, p>.05$. Of more

5 central interest, the ANOVA revealed a significant Activity x Time interaction, $F(1,175)=5.80$,

$6 p<.05, \eta^{2}=.03$; the mountaineers experienced a greater decrease in anxiety $\left(M_{T 1}=17.48, S D=\right.$

710.57 to $\left.M_{T 2}=11.22, S D=9.89, p<.001\right)$ than did the judokas $\left(M_{T 1}=15.99, S D=5.13\right.$ to $M_{T 2}=$

$8 \quad 12.70, S D=4.92, p<.01)$.

9 To test the specificity of high-risk sport in the process of anxiety self-regulation, we

10 performed moderated hierarchical regression analyses on the anxiety difference, $Y_{d}\left(Y_{2}-Y_{1}\right)$,

11 following procedures described by Aiken and West (1991). All variables were centered before

12 being subjected to regression analyses. For the purpose of these analyses the sport group variable

13 (judo and mountaineering) was dummy-coded. For each analysis, age was controlled at Step 1,

14 self-regulation strategy (i.e., escape or compensation) and sport group were entered at Step 2 and

15 the self-regulation strategy $\times$ sport group interaction term was entered at Step 3 .

16 Escape. After controlling for age in the first step $(\beta=-.08, n s)$, the analysis revealed an

17 incremental proportion of variance $\left(\Delta R^{2}=.07, p<.01\right)$ at the second step, with significant

18 contributions of escape strategy $(\beta=-.21, p<.01)$ and sport group $(\beta=-.30, p<.05)$. The escape

19 strategy $\times$ sport group interaction term further accounted for a significant proportion of variance

20 over and above the main effects, $\Delta R^{2}=.04, p<.01$. The slope for the escape strategy $\times$ sport

21 group interaction was significantly different from zero, $t(173)=2.61, p<.01, \eta^{2}=.04$. In the

22 mountaineering equation, Escape was a significant predictor of the anxiety decrease, $t(173)=$

$233.79, p<.01, \eta^{2}=.08$. Conversely, in the judo equation, the slope for Escape was not 
1 significantly different from zero, $t(173)=0.06, p>.50, \eta^{2}<.01$. This significant escape strategy

$2 \times$ sport group interaction shows that higher escape profiles yielded greater decreases in anxiety

3 for mountaineers only, as hypothesized.

$4 \quad$ Compensation. After controlling for age in the first step, the analysis revealed an

5 incremental proportion of variance $\left(\Delta R^{2}=.03, p<.05\right)$ at the second step, with a significant

6 contribution of sport group only $(\beta=-.32, p<.05)$. Entered in the third step, the compensation

7 strategy $\times$ sport group interaction term did not account for a significant proportion of variance

8 over and above the main effects, $\Delta R^{2}=.00, n s$.

\section{Discussion}

10 The aim of the present study was to investigate the change in affect intensity from before

11 to after a risk-taking sport activity and the moderating role of self-regulation strategies therein.

12 The hypotheses were partially supported. Anxiety significantly decreased from pre- to post-

13 mountain route and the more mountaineers used escape strategy the more their anxiety decreased.

14 This result suggests that mountaineers who participate for escape motives derive an important

15 emotional benefit from completing a mountain route. This emotional benefit was limited to a

16 decrease in negative affect (i.e., anxiety) and did not extend to an increase in positive affect.

17 In line with Taylor and Hamilton (1997), escape was significantly correlated with

18 mountaineers' general tendency to feel negative affects (i.e., negative affectivity). Given the

19 generalized negative affect for escape mountaineers, the elevated anxiety before the mountain

20 route for these persons was likely somewhat linked to general affective distress rather than to the

21 anxiety that might be provoked specifically by the mountain climb. In this way, one could argue

22 that mountaineering serves an anxiety regulation function for those individuals who seek to

23 escape from self-awareness and not to think of their ill-being (Cazenave et al., 2007; Lafollie \& 
1 Le Scanff, 2007; Woodman et al., 2009). Thus, high-risk sport involvement for these individuals

2 might be motivated specifically by the desire to decrease anxiety.

4 anxiety rather than globalized negative affect. Mountaineering is a sport where the possibility of

5 severe injury or death is an inherent part of the activity (Breivik, 1995; Llewellyn \& Sanchez,

6 2008). Thus, the danger of mountaineering induces external and specific fear that may allow

7 escape-motivated individuals to move their non-specific and internal source of anxiety to a more

8 externally-derived anxiety (Fenichel, 1939; Woodman et al., 2008). Moreover, mountaineering is

9 a demanding activity that involves aerobic and strength capacities, and requires a high level of

10 physiological activation (Fyffe \& Peter, 1997). Thus, as high-risk sports allow one to regulate the

11 physiological arousal associated with anxiety, involvement in these activities would be a better

12 emotion regulation strategy for anxious individuals than disinhibition behaviors such as substance

13 abuse.

14 Conversely, low escape participants had relatively low negative affectivity and

15 experienced low and stable anxiety throughout the mountain route. This seems to suggest that the

16 underlying motive for engagement in mountaineering for low escape individuals was not the

17 desire to regulate negative affect. Thus, it would be misleading to view these risk-taking activities

18 as a unitary phenomenon that is associated with poor psychological functioning and notably

19 emotional distress (Taylor \& Hamilton, 1997). For certain individuals the involvement in high-

20 risk sport might represent psychologically healthy and fulfilling goal-directed behavior.

$21 \quad$ No significant relation was revealed between mountaineers' compensation strategy and

22 affect change, which suggests that the compensation strategy is not directly linked to affect

23 regulation in high-risk sport. According to Taylor and Hamilton (1997), the compensation self-

24 regulation strategy is enacted by individuals with a healthy self-concept comprising multiple 
1 independent sources of self-worth and is unrelated to indicators of psychological distress. The

2 present data support this lack of association between compensation and negative affect. It seems,

3 therefore, that compensation-oriented persons do not need to engage in high-risk sport in order to

4 regulate their affect. For such individuals the engagement in high-risk sports likely serves another

5 compensation function such as self-image regulation. This is likely an important motive

6 specifically for mountaineers given their elevated compensation scores in relation to more

7 traditional and competitive sports (i.e., judo). Clearly, further research is necessary to understand

8 the motives underlying low escape persons' and high compensation persons' participation in

9 high-risk activities.

10 The results revealed that the anxiety self-regulation process was specific to high-risk

11 sport. Only escape mountaineers derived an immediate emotional benefit (i.e., a decrease in

12 anxiety) from their activity. No such effect was revealed for the judokas. These results suggest

13 that it is the high-risk specificity of mountaineering that allows one to regulate anxiety in the

14 sport domain. Indeed, the high level of attention required in high-risk sport would allow

15 individuals to shift attention away from their internal anxiety (Taylor \& Hamilton, 1997).

16 Moreover, according to Fenichel's (1939) counter-phobic theory the risk-taking domain may be

17 attractive to individuals who have high anxiety, as it affords them an opportunity to initiate and

18 experience a more externally-derived anxiety. That is, the individual's negative, non-specific, and

19 internal source of anxiety may be transferred to an external and specific task (e.g.,

20 mountaineering) thus allowing him/her to experience some respite from the internal fear (see also

21 Woodman et al., 2008). Thus, the practice of high-risk-sport may be a means of anxiety

22 regulation, allowing some people to experience an emotional benefit that they do not experience

23 elsewhere (Barlow et al., 2007; Taylor \& Hamilton, 1997; Woodman et al., 2009). 
Despite promising results, the current study has some limitations that should be

2 considered in further research. First, the nature of the anxiety that is experienced needs closer

3 attention. In the present line of research, the anxiety that was of interest was of a more general

4 nature than is typically investigated in sport settings. Specifically, in the current study, we were

5 interested in how mountaineering might help mountaineers deal with their emotions and

6 specifically their anxiety. This was clearly not competitive anxiety and measuring competitive

7 anxiety would clearly have been inappropriate. However, the anxiety typically experienced in

8 sport is largely thought to be directly related to the impending competition and researchers

9 typically thus investigate the different dimensions of the competitive anxiety response. These

10 include cognitive anxiety, somatic anxiety, physiological arousal, concentration disruption, and

11 perceived control (cf. Cheng, Hardy, \& Markland, 2009; Grossbard, Smith, Smoll, \& Cumming,

12 2009; Woodman \& Hardy, 2001). Future research on the anxiety benefits of mountaineering

13 should also consider a more fine-grained measurement of anxiety.

14 Moreover, the data should be interpreted with some caution given that they were collected

15 over a relatively short period of time with no information about the affective experience during

16 the activity itself. Certainly, it remains empirically unclear whether the high anxiety of escape

17 individuals before the mountain route is linked to global emotional distress, to the specific

18 situation, or both. Furthermore, our data do not allow us to establish what the perceived (failure

19 and success) experiences are that might lead people to engage in mountaineering in the first

20 place. There are some early signs that some of the perceived failure may be in feelings of limited

21 agency in personal relationships, which may go some way to explaining why people engage in

22 such an emotion-inducing activity rather than other activities that may provide self-worth (e.g.,

23 judo). In other words, there may be some sort of emotional transfer of anxiety from personal

24 relationships to the high-risk domain (Barlow et al., 2007). As Lester $(1983 ; 2004)$ pointed out, 
1 some mountaineers perceive personal relationships and interactions as more stressful than a very

2 difficult and dangerous situation in the mountains. Although this theoretical link is very much

3 related to the present data, these data do not allow us to draw such conclusions with any

4 confidence. Thus, future research should be conducted to investigate this interesting question.

5 A further limitation of the present study is that we obtained no information about the

6 duration of the affective benefits after completion of the mountain route. As the escape strategy is

7 positively related to trait anxiety (Taylor \& Hamilton, 1997), escape mountaineers may return to

8 their high-anxiety base level shortly after completing the route. In line with Woodman et al.

9 (2008), the affect regulation function of high-risk sport may not serve a long-term regulation

10 function for individuals with emotional distress, and they might feel the need to repeat the

11 activity to derive a continued renewed sense of emotional benefit (see also Fenichel, 1939). The

12 pre-occupation with, and the continued involvement in, an activity despite potential negative

13 consequences is typically viewed as behavior addiction (Price \& Bundesen, 2005). To address

14 these questions future research should consider affect states over longer periods of time, before

15 and after participation in high-risk sport.

16 Contrary to many high-risk sports such as skydiving or downhill skiing, mountaineering is

17 an activity that can last several hours, days, or weeks and during which much can happen. This

18 specificity of mountaineering makes it difficult to generalize the results to other high-risk sports.

19 Thus, other sport activities and indeed other less socially acceptable risk-taking activities (e.g.,

20 dangerous driving) warrant further specific investigation within the affect regulation framework

21 outlined here. Furthermore, because the population study included only male athletes, we cannot

22 generalize the results to more global populations (see also Cazenave et al., 2007; Woodman et al., 23 2008). 
1 In summary, the current study revealed that only escape from self-awareness as a self-

2 regulation strategy resulted in significant changes in negative affect intensity, specifically a

3 decrease in anxiety, from pre- to post-mountain route. These results contribute to an ongoing in-

4 depth understanding of the affect regulation function that high-risk sport might serve, especially

5 for persons with emotional difficulties. 


\section{References}

Aiken, L. S., \& West, S. G. (1991). Multiple regression: Testing and interpreting interactions. Newbury Park: CA: Sage.

Arnett, J. J. (1996). Sensation seeking, aggressiveness, and adolescent reckless behavior. Personality and Individual Differences, 20(6), 693-702. doi:10.1016/01918869(96)00027-X

Barlow, M., Hardy, L., \& Woodman, T. (2007). "Because it's there"? A re-examination of the motives for participation in serious mountaineering. $12^{\text {th }}$ European Congress of Sport Psychology (FEPSAC). Halkidiki, Greece.

Bless, H., \& Forgas, J. P. (2000). The message within: The role of subjective experience in social cognition. Philadelphia: Psychology Press.

Breivik, G. (1995). Personality, sensation seeking and arousal in high risk sports. Oslo: Norwegian University of Sport and Physical Education.

Carver, C. S., \& Scheier, M. F. (1981). Attention and self-regulation: A control theory approach to human behaviour. New-York: Springer-Verlag.

Cazenave, N., Le Scanff, C., \& Woodman, T. (2007). Psychological profiles and emotional regulation characteristics of women engaged in risk-taking sports. Anxiety, Stress, and Coping, 20(4), 421-435. doi:10.1080/10615800701330176

Cheng, W-N. K., Hardy, L., \& Markland, D. (2009). Toward a three-dimensional conceptualization of performance anxiety: Rationale and initial measurement development. Psychology of Sport and Exercise, 10, 271-278. doi:10.1016/j.psychsport.2008.08.001 
Cooper, M. L., Agocha, V. B., \& Sheldon, M. S. (2000). A motivational perspective on risky behaviors: The role of personality and affect regulatory processes. Journal of Personality, 68, 1059-1088. doi:10.1111/1467-6494.00126

Cooper, M. L., Shapiro, C. M., \& Powers, A. M. (1998). Motivations for sex and risky sexual behavior among adolescents and young adults: A functional perspective. Journal of Personality and Social Psychology, 75, 1528-1558. doi:10.1037/0022-3514.75.6.1528

Diener, E., \& Seligman, M. (2002). Very happy people. Psychological Science, 13(1), 81-84. doi:10.1111/1467-9280.00415

Diener, E., Smith, H., \& Fujita, F. (1995). The personality structure of affect. Journal of Personality and Social Psychology, 69(1), 130-141. doi:10.1037/0022-3514.69.1.130

Duval, S., \& Wicklund, R. A. (1972). A theory of objective self-awareness. New York: Academic Press.

Ewert, A. W. (1994). Playing the edge: Motivation and risk taking in a high-altitude wilderness environment. Environment and Behavior, 26(1), 3-24. doi:10.1177/0013916594261001

Fenichel, O. (1939). The Counter-Phobic Attitude. International Journal of Psychoanalysis, 20, 263-274.

Ferrando, P. J., \& Chico, E. (2001). The construct of sensation seeking as measured by Zuckerman's SSS-V and Arnett's AISS: A structural equation model. Personality and Individual Differences, 31, 1121-1133. doi:10.1016/S0191-8869(00)00208-7

Fyffe, A., \& Peter, I. (1997). The handbook of climbing (2nd ed.). London: Pelham Books. Gross, J. J. (1999). Emotion regulation : Past, present, future. Cognition and Emotion, 13(5), 551573. doi:10.1080/026999399379186 
Grossbard, J.R., Smith, R.E., Smoll, F.L., \& Cumming, S.P. (2009). Competitive anxiety in young athletes: Differentiating worry, somatic anxiety, and concentration disruption. Anxiety, Stress, \& Coping, 22, 153-156. doi:10.1080/10615800802020643

Hamilton, J. C., Greenberg, J., Pyszczynski, T., \& Cather, C. (1993). A self-regulatory perspective on psychopathology and psychotherapy. Journal of Psychotherapy Integration, 3, 205-248.

Himelstein, P., \& Thorne, S. B. (1985). Relationship between the Sensation Seeking Scale and a biographical inventory designed to predict risk-taking behavior. Personality and Individual Differences, 6(1), 121-122. doi:10.1016/0191-8869(85)90037-6

Horvath, P., \& Zuckerman, M. (1993). Sensation seeking, risk appraisal, and risky behavior. Personality and Individual Differences, 14(1), 41-52. doi:10.1016/0191-8869(93)90173-Z

Hoyle, R. H., Fejfar, M. C., \& Miller, J. D. (2000). Personality and sexual risk-taking: a quantitative review. Journal of Personality, 68, 1203-1231. doi:10.1111/1467-6494.00132

Jackson, J., \& Maraun, M. (1996). The conceptual validity of empirical scale construction: The case of the sensation seeking scale. Personality and Individual Differences, 21(1), 103110. doi:10.1016/0191-8869(95)00217-0

Jelalian, E., Alday, S., Spirito, A., Rasile, D., \& Nobile, C. (2000). Adolescent motor vehicle crashes : The relationship between behavioural factors and self-reported injury. Journal of Adolescent Health, 27, 84-93. doi:10.1016/S1054-139X(00)00098-7

Judd, C. M., Kenny, D. A., \& McClelland, G. H. (2001). Estimating and testing mediation and moderation in within-subject designs. Psychological Methods, 6(2), 115-134. doi:10.1037/1082-989X.6.2.115 
Lafollie, D., \& Le Scanff, C. (2007). Détection des personnalités à risque dans les sports à sensations fortes. [Detection of high-risk personalities in risky sports]. L'Encéphale, 33, 135-141. doi:10.1016/S0013-7006(07)91543-2

Lafollie, D., Le Scanff, C., \& Fontayne, P. (2008). Adaptation française de "l'Inventaire de risque et d'activation" (IRA). [French adaptation of "the Risk and Excitement Inventory" (REI)]. Canadian Journal of Behavioural Science, 40(2), 113-119. doi:10.1037/0008400X.40.2.113

Larsen, R. J. (2000). Maintaining hedonic balance: Reply to commentaries. Psychological Inquiry, 11, 218-225. doi:10.1207/S15327965PLI1103_07

Larsen, R. J., \& Prizmic, Z. (2004). Affect regulation. In R. F. Baumeister \& K. D. Vohs (Eds.), Handbook of Self-Regulation (pp. 40-61). New York: Guilford Press.

Lester, J. T. (1983). Wrestling with the Self on Mount Everest. Journal of Humanistic Psychology, 23(2), 31-41. doi:10.1177/0022167883232005

Lester, J. T. (2004). Spirit, Identity, and Self in Mountaineering. Journal of Humanistic Psychology, 44(1), 86-100. doi:10.1177/0022167803257111

Llewellyn, D. J., \& Sanchez, X. (2008). Individual differences and risk taking in rock climbing. Psychology of Sport and Exercise, 9, 413-426. doi:10.1016/j.psychsport.2007.07.003

Michel, G., Carton, S., \& Jouvent, R. (1997). Recherche de sensations et anhédonie dans les conduites de prise de risque. Etude d'une population de sauteurs à l'élastique (benji). [Sensation seeking and anhedonia in risk taking behaviors. A study of bungee jumpers]. L'Encéphale, 23(6), 403-411.

Parkinson, B., Totterdell, P., Briner, R. B., \& Reynolds, S. (1996). Changing Moods: The. Psychology of Mood and Mood Regulation. London: Longman. 
Pelissolo, A., Rolland, J. P., Perez-Diaz, F., Jouvent, R., \& Allilaire, J. F. (2007). Evaluation dimensionnelle des émotions en psychiatrie : validation du questionnaire Emotionnalité positive et négative à 31 items (EPN-31). [Dimensional evaluation of emotions in psychiatry: validation of the EPN-31]. L'Encéphale, 33(3), 256-263. doi:10.1016/S00137006(07)92037-0

Price, I. R., \& Bundesen, C. (2005). Emotional changes in skydivers in relation to experience. Personality and Individual Differences, 38, 1203-1211. doi:10.1016/j.paid.2004.08.003

Pyszczynski, T., Greenberg, J., Solomon, S., \& Hamilton, J. C. (1991). A terror management analysis of self-awareness and anxiety: The hierarchy of terror. Anxiety Research, 2(3), 177-195.

Shapiro, R., Siegel, A. W., Scovill, L. C., \& Hays, J. (1998). Risk-taking patterns of female adolescents: what they do and why. Journal of Adolescence, 21(2), 143-159. doi:10.1006/jado.1997.0138

Slanger, E., \& Rudestam, K. E. (1997). Motivation and Disinhibition in High Risk Sports: Sensation Seeking and Self-Efficacy. Journal of Research in Personality, 31(3), 355-374. doi:10.1006/jrpe.1997.2193

Tabachnick, B. G., \& Fidell, L. S. (2001). Using multivariate statistics (4th ed.). Boston, MA: Allyn \& Bacon.

Taylor, R. L., \& Hamilton, J. C. (1997). Preliminary evidence for the role of self-regulatory processes in sensation seeking. Anxiety, Stress, and Coping, 10, 351-375. doi:10.1080/10615809708249309

Thompson, R. A. (1994). Emotion regulation: A theme in search of definition. Monographs of the Society for Research in Child Development, 59, 25-52. doi:10.2307/1166137 
Turner, C., McClure, R., \& Pirozzo, S. (2004). Injury and risk-taking behavior-a systematic review. Accident Analysis and Prevention, 36, 93-101. doi:10.1016/S00014575(02)00131-8

Van Hasselt, V. B., Null-Tracy Kempton, J. A., \& Bukstein, O. G. (1993). Social skills and depression in adolescent substance abusers. Addictive Behaviors, 18, 9-18. doi:10.1016/0306-4603(93)90004-S

Woodman, T., Cazenave, N., \& Le Scanff, C. (2008). Skydiving as emotion regulation: The rise and fall of anxiety is moderated by alexithymia. Journal of Sport and Exercise Psychology, 30, 424-433.

Woodman, T., \& Hardy, L. (2001). Stress and Anxiety. In R. N. Singer, H. A. Hausenblas, \& C. M. Janelle (Eds.), Handbook of Sport Psychology (pp. 290-318) New York: Wiley. Woodman, T., Hardy, L., Barlow, M., \& Le Scanff, C. (under second review). Motives for prolonged engagement high-risk sports: An agentic emotion regulation perspective. Psychology of Sport and Exercise.

Woodman, T., Hardy, L., \& O'Brien, G. (2005). Why do people choose to cross the Atlantic Ocean in a rowing boat? An emotional regulation perspective. $20^{\text {th }}$ annual conference of the Association for Applied Sport Psychology (AASP), Vancouver, Canada.

Woodman, T., Huggins, M., Le Scanff, C., \& Cazenave, N. (2009). Alexithymia determines the anxiety experienced in skydiving. Journal of Affective Disorders, 116, 134-138. doi:10.1016/j.jad.2008.11.022

Zuckerman, M. (1994). Behavioral Expressions and Biosocial Bases of Sensation Seeking. New York: Cambridge University Press.

Zuckerman, M. (2007). Sensation seeking and risky behavior. Washington, DC: American Psychological Association. doi:10.1037/11555-000 
Affect regulation in mountaineering 25

\begin{abstract}
Author note
The authors would like to thank the editor and three anonymous reviewers for their helpful and insightful comments and suggestions on an earlier draft of this manuscript and Paul Fontayne for his help with the statistical analyses.
\end{abstract}


Table 1

Correlations between variables study for mountaineers $(\mathrm{N}=105)$.

\begin{tabular}{|c|c|c|c|c|c|c|c|c|c|c|c|c|c|c|c|}
\hline & 1. & 2. & 3. & 4. & 5. & 6. & 7. & 8. & 9. & 10. & 11. & 12. & 13. & 14. & 15. \\
\hline 1. Age & - & & & & & & & & & & & & & & \\
\hline 2. Escape & -.27 & - & & & & & & & & & & & & & \\
\hline 3. Compensation & -.10 & .21 & - & & & & & & & & & & & & \\
\hline 4. Negative affectivity & -.16 & .41 & .13 & - & & & & & & & & & & & \\
\hline 5. Anxiety $\mathrm{T} 1$ & -.06 & .35 & -.02 & .45 & - & & & & & & & & & & \\
\hline 6. Anger T1 & -.04 & .20 & .02 & .32 & .47 & - & & & & & & & & & \\
\hline 7. Shame T1 & -.18 & .19 & .15 & .39 & .43 & .63 & - & & & & & & & & \\
\hline 8. Sadness T1 & -.18 & .18 & .05 & .39 & .46 & .50 & .66 & - & & & & & & & \\
\hline 9. Joy T1 & .04 & .01 & .06 & .04 & .04 & -.04 & .02 & -.02 & - & & & & & & \\
\hline 10. Affection T1 & .11 & .02 & .05 & .01 & .09 & .09 & .16 & .19 & .69 & - & & & & & \\
\hline 11. Anxiety T2 & .04 & .04 & .03 & .27 & .46 & .26 & .27 & .21 & -.01 & -.03 & - & & & & \\
\hline 12. Anger T2 & .06 & .06 & .09 & .24 & .27 & .41 & .33 & .20 & -.05 & -.09 & .40 & - & & & \\
\hline 13. Shame T2 & -.11 & .18 & .12 & .35 & .42 & .34 & .65 & .47 & -.06 & .05 & .54 & .61 & - & & \\
\hline 14. Sadness T2 & -.17 & .18 & .03 & .35 & .35 & .22 & .35 & .67 & -.08 & .04 & .44 & .26 & .55 & - & \\
\hline 15. Joy T2 & .02 & .12 & .09 & .08 & .03 & .03 & .01 & -.06 & .66 & .48 & .04 & -.15 & -.12 & -.07 & - \\
\hline 16. Affection T2 & .07 & .05 & .04 & .04 & .11 & .08 & .20 & .16 & .60 & .87 & .09 & -.04 & .11 & .11 & .62 \\
\hline
\end{tabular}

Note: All correlations $\geq|.20|$ are significant at $p<.05$. 
Table 2

Single-factor repeated measures (pre/post activity) ANCOVAs with each affect as the dependent variable and age as the covariate for mountaineers $(\mathrm{N}=105)$ and for judokas $(\mathrm{N}=73)$

\begin{tabular}{|c|c|c|c|c|c|c|}
\hline & \multicolumn{2}{|c|}{ Pre-mountain route } & \multicolumn{2}{|c|}{ Post-mountain route } & \multirow{2}{*}{$F(1,103)$} & \multirow{2}{*}{$\eta^{2}$} \\
\hline & $M$ & $S D$ & $M$ & $S D$ & & \\
\hline Anxiety & 17.48 & 10.57 & 11.22 & 9.89 & $4.39 *$ & .04 \\
\hline Anger & 3.22 & 5.31 & 2.65 & 4.83 & 1.23 & .01 \\
\hline Shame & 4.62 & 6.18 & 4.42 & 5.96 & 1.46 & .01 \\
\hline Sadness & 6.14 & 7.70 & 4.88 & 7.34 & 0.45 & .00 \\
\hline Joy & 50.41 & 13.85 & 50.12 & 15.12 & 0.03 & .00 \\
\hline \multirow[t]{3}{*}{ Affection } & 43.47 & 19.59 & 41.11 & 20.19 & 0.04 & .00 \\
\hline & \multicolumn{2}{|c|}{ Pre- judo fight } & \multicolumn{2}{|c|}{ Post- judo fight } & & \\
\hline & $M$ & $S D$ & $M$ & $S D$ & & \\
\hline Anxiety & 15.99 & 5.13 & 12.70 & 4.92 & 2.35 & .03 \\
\hline Anger & 2.89 & 3.48 & 2.92 & 4.11 & 0.03 & .00 \\
\hline Shame & 7.03 & 3.23 & 5.19 & 4.77 & 0.27 & .00 \\
\hline Sadness & 7.93 & 3.72 & 8.74 & 4.39 & 0.01 & .00 \\
\hline Joy & 48.74 & 4.93 & 49.59 & 5.06 & 1.43 & .02 \\
\hline Affection & 37.78 & 4.65 & 41.05 & 4.97 & 0.05 & .00 \\
\hline
\end{tabular}

Note: $* p<.05$ 
Affect regulation in mountaineering 28

Table 3

Regression analyses for each affect type of mountaineers $(\mathrm{N}=105)$ on self-regulation strategy (i.e., escape or compensation) after controlling for age.

\begin{tabular}{|c|c|c|}
\hline T1 affect & T2 affect & T2-T1 affect \\
\hline$t(102)$ & $t(102)$ & $t(102)$ \\
\hline
\end{tabular}

Escape moderation

\begin{tabular}{lcccccc}
\hline Anxiety & 1.02 & $3.68^{* *}$ & 0.15 & 0.56 & -0.87 & $-3.06^{* *}$ \\
Anger & 0.35 & 1.95 & 0.12 & 0.87 & -0.18 & -1.03 \\
Shame & 0.33 & 1.87 & 0.20 & 1.04 & -0.14 & -0.79 \\
Sadness & 0.37 & 1.78 & 0.29 & 1.47 & -0.08 & -0.45 \\
Joy & 0.08 & 0.21 & 0.57 & 1.35 & 0.49 & 1.46 \\
Affection & 0.31 & 0.57 & 0.41 & 0.73 & 0.10 & 0.37 \\
\hline Compensation moderation & & & & & & \\
\hline Anxiety & -0.06 & -0.24 & 0.08 & 0.33 & 0.14 & 0.55 \\
Anger & 0.02 & 0.16 & 0.11 & 0.98 & 0.09 & 0.70 \\
Shame & 0.19 & 1.33 & 0.16 & 1.16 & -0.03 & -0.23 \\
Sadness & 0.05 & 0.29 & 0.03 & 0.18 & -0.02 & -0.15 \\
Joy & 0.22 & 0.66 & 0.35 & 0.99 & 0.14 & 0.48 \\
Affection & 0.65 & 0.23 & 0.48 & -0.07 & -0.29 \\
\hline
\end{tabular}

Note: $* * p<.01$ 